\title{
“MILO MI PANA POZNAĆ” (MUITO PRAZER) ... ESCOLA \\ MULTISSERIADA DA LINHA POLONESA, UMA ORGANIZAÇÃO ÉTNICA DO INÍCIO DO SÉCULO XX (MUNICÍPIO DE CRUZ MACHADO - PR) ${ }^{1}$
}

\author{
"MIŁO MI PANA POZNAC"” (Very Pleased) ... Multiseried School of \\ the Polish line, an Ethnic Organization from the Early 20th Century \\ (Municipality of Cruz Machado - PR)
}

Vanessa FEDEROVICZ Universidade Estadual do Paraná (UNESPAR), campus de União da Vitória. vanessafederovicz2428@gmail.com http://orcid.org/0000-0002-9078-3322

Roseli B. KLEIN Universidade Estadual do Paraná (UNESPAR), campus de União da Vitória. roseli.klein@hotmail.com http://orcid.org/0000-0002-3368-5785.

RESUMO: A Escola Presidente Costa e Silva da Linha Polonesa, criada no ano de 1970, área rural do Município de Cruz Machado (PR), foi organizada por descendentes dos primeiros imigrantes poloneses, que chegaram a região no início do século XX. Essas escolas, na modalidade multisseriada, perduraram por longo tempo em áreas rurais distantes dos grandes centros e, algumas delas, alcançaram o século XXI. A criação dessa instituição, na Linha Polonesa, teve como proposta oferecer ensino público às crianças da pequena comunidade local. A pesquisa teve por objetivo resgatar dados de fundação e funcionamento do espaço escolar destacando as práticas educativas vivenciadas na instituição. Justifica-se o estudo pelo fato dessas escolas isoladas e multisseriadas serem um espaço de escolarização destinado ao meio rural brasileiro, no sul do país, em pequenas e longínquas comunidades. Utiliza-se de pesquisa descritiva, bibliográfica, exploratória e pesquisa de campo através da história e memória oral. O referencial teórico que norteia essa investigação pauta-se nos estudos sobre imigração polonesa de Renk (2013) e nos estudos sobre cultura escolar de Julia (2001). PALAVRAS-CHAVE: Escolarização do imigrante; Práticas educativas; Cultura escolar.

\footnotetext{
${ }^{1}$ Artigo resultante do Trabalho de Conclusão de Curso de Vanessa Federovicz.
} 


\begin{abstract}
The Presidente Costa e Silva School of the Polish Line, created in 1970, a rural area in the municipality of Cruz Machado (PR), was organized by descendants of the first Polish immigrants, who arrived in the region in the early 20th century. These schools, in the multiseriate modality, lasted for a long time in rural areas far from large centers and, some of them, reached the 21st century. The creation of this institution, on the Polish Line, aimed to offer public education to children in the small local community. The research aimed to rescue data on the foundation and functioning of the school space, highlighting the educational practices experienced in the institution. The study is justified by the fact that these isolated and multiserial schools are a schooling space for the Brazilian rural environment, in the south of the country, in small and remote communities. It uses descriptive, bibliographic, exploratory and field research through document analysis, and history and oral memory. The theoretical framework that guides this investigation is based on Renk's studies on Polish immigration (2013) and Julia's studies on school culture (2001). KEYWORDS: Immigrant schooling; Educational practices; School culture.
\end{abstract}

\title{
INTRODUÇÃO
}

Europeus de diversas procedências aportaram nas terras luso-brasileiras por meio do processo colonizador. Esses encontraram várias adversidades e tiveram que se organizar em comunidades para a própria sobrevivência. Perpetuaram nas áreas coloniais características de atividade agrícola sistematizadas na pequena propriedade e através do padrão de distribuição de terras, destacando os modos de constituição dos núcleos familiares. Entre os fatores organizacionais fundaram pequenas escolas étnicas com o objetivo de oferecer um mínimo de educação para seus filhos. Segundo Kreutz (2000) a preocupação com a escola manifestava-se porque os imigrantes vinham de regiões com um nível de escolarização elevado e atribuíam a ela um meio de preservar a identidade cultural, a língua, os costumes e as crenças pertencentes ao país de origem.

Os poloneses chegaram ao Município de Cruz Machado por volta de 1911. O núcleo de colonização foi fundado pelo Governo Federal (1910), com o intuito de colonizar grandes áreas do território paranaense. Recebeu imigrantes poloneses e ucranianos que criaram suas próprias escolas atendidas por professores particulares, fundaram associações culturais e recreativas, sociedades de apoio e de ajuda mútua, conquistaram sua nova pátria oportunizando desenvolvimento por meio da ocupação das terras.

A pesquisa teve por objetivo levantar dados sobre a fundação da escola e sobre o 
funcionamento do espaço escolar, destacando a prática pedagógica/educativa da Escola Presidente Costa e Silva, na comunidade Linha Polonesa, pertencente ao Município de Cruz Machado (PR). A investigação apresenta-se bibliográfica, descritiva exploratória com pesquisa de campo realizada por meio da história e memória oral dos sujeitos envolvidos. O estudo delineia-se pela linha teórica da história cultural.

As circunstâncias vividas pelas escolas estabelecidas em núcleos étnicos constituem-se como ponto relevante de estudo e, concomitantemente, apresentam-se como proposta inédita de investigação devido ao fato de que a escola, ainda, permanece em funcionamento na modalidade multisseriada e permanece presente na memória dos alunos e professores que a frequentaram.

\section{OS IMIGRANTES POLONESES: NÚCLEOS COLONIAIS E A ORGANIZA- ÇÃO DA ESCOLA}

O povo polonês cansado das dificuldades que assolavam o seu país foi atraído pelas propagandas sobre as terras brasileiras que anunciavam clima favorável e terras férteis. Porém, ao chegarem perceberam que os anúncios eram ilusórios, encontraram matas fechadas, pouca comida e falta de acomodações ${ }^{2}$. Estabeleceram-se no Brasil no final do século XIX e início do século XX, período intenso de imigração, principalmente no estado do Paraná.

Oferecer educação aos seus filhos tornou-se uma preocupação por consistir num modo de preservar a cultura de origem, a língua e os costumes. Iniciaram a construção de escolas de forma comunitária, desde a construção até a manutenção, inclusive encarregando-se do pagamento dos serviços do professor. Havia precariedade quanto a aquisição do material didático, pois os recursos escassos não permitiam a aquisição dos mesmos. Utilizavam, muitas vezes, materiais religiosos, como por exemplo, a bíblia e o catecismo.

Religiosos católicos adentraram esses espaços para auxiliarem os colonos, interviram na manutenção e preservação da fé e da cultura polonesa, fundaram a Igreja e cooperaram com o surgimento da Escola. Em grande parte, os padres foram os responsáveis pelas construções das escolas para os filhos de imigrantes, foram eles que ajudaram a diminuir o analfabetismo nas colônias (WACHOWICZ, 1981). Essa empatia

\footnotetext{
${ }^{2}$ Segundo Rockenbach (1996) ao chegarem na região sul do Paraná, na localidade de Cruz Machado, foram acomodados em "butkas", pequenas casinhas, sem muitas condições higiênicas, até que construíssem suas próprias casas.
} 
com o catolicismo aproximou as congregações religiosas dessas localidades e a Igreja auxiliou na organização da vida social desses povos.

Renk (2013) ressalta que a criação dessas escolas rurais isoladas levava a ausência de professores qualificados para lecionarem, então escolhia-se uma pessoa da própria comunidade para assumir essa função, geralmente alguém com algum tipo de educação em nível mais elevado, ou até mesmo, mais propenso a leituras e estudos. Referindo-se a realidade do Município de Cruz Machado, Rockenbach (1996, p. 28) cita que "desde a chegada dos imigrantes, quanto ao ensino às crianças, era proporcionado por entidades particulares e religiosas, ou mesmo os pais dos alunos contratavam e remuneravam os professores [...]". Apesar do ensino ser importante as condições econômicas adversas dessa população tornavam o salário dos professores insuficiente. Esse fato agregado as adversidades da docência obrigavam os mestres a desenvolverem outras atividades para garantir sua sobrevivência (MALIKOSKI; KREUTZ, 2017).

A alfabetização, na língua pátria desses povos, consistia numa preocupação para a escolarização da população brasileira tendo em vista que, dessa forma, seria difícil uniformizar o ensino no país. Órgãos representativos da educação no Brasil, juntamente com seus representantes, começaram a pensar algumas propostas desde o início do século XX. Martiniak (2013) ressalta que a proposta de nacionalização vinha sendo pensada desde o ano de 1900, entretanto a obrigatoriedade do ensino na língua nacional, em todas as escolas, se efetivou com o Decreto de Lei ${ }^{\circ}$ 406, de 04 de maio 1938.

Renk (2008) destaca que, entre os anos de 1900 a 1938, enfatizava-se o ensino na língua nacional. Para que isso se efetivasse, no decorrer do tempo, criaram-se algumas leis para dar apoio a esta proposta. Em 19 de abril de 1909 ocorreu uma reforma no ensino, com a lei $n^{\circ} 894$, que estipulava a obrigatoriedade do ensino em língua nacional nas escolas e também gerava multa a quem não a obedecesse. Em 1917, com o Decreto Lei $n^{\circ} 17$, Art. 4, permitiu-se que fossem efetuadas inspeções nas escolas, com o intuito de fiscalizar o ensino, eliminando o uso da língua de origem. A proposta tornou-se mais rígida, através da Lei $\mathrm{n}^{\circ} 2.005$, que exigia o ensino na língua vernácula, e incentivava os estudos sobre a história do Brasil, sua geografia e também o português.

Em 1922, no estado do Paraná, em continuidade a este processo, o Decreto Lei $n^{\circ} 2.157$ exigiu professores aptos com mais capacidade e competência para ministrarem as aulas na língua nacional. Também reivindicou o respeito aos feriados nacionais e a obrigatoriedade das disciplinas de história e geografia do Brasil no currículo escolar. E por fim, o Decreto Lei $n^{\circ} 406$, de 1938, anulou a atuação das escolas étnicas. Renk (2008) destaca que a legislação abalou o funcionamento das escolas étnicas. No final do ano de 
1938, a Lei $n^{\circ} 7.614$ veio complementar a Lei $n^{\circ} 406$, enfatizando, mais uma vez, que o ensino somente poderia acontecer em língua portuguesa. Um passo muito importante para esse processo aconteceu no ano seguinte, em 1939, com a Lei ${ }^{\circ} 1.545$ que direcionava a construção de escolas públicas nas áreas em que os imigrantes estavam estabelecidos, exigindo relevância ao patriotismo e fiscalização mais intensa em relação ao ensino das línguas estrangeiras.

As escolas dos imigrantes tiveram que se adaptar a nova legislação, priorizando o ensino da língua pátria, adotando noções de civismo como o ensino do hino nacional, o respeito pela bandeira nacional e os estudos da história e geografia do Brasil. Renk (2013) afirma que para manter a cultura viva, os imigrantes tiveram que criar meios para continuar ensinando a língua polonesa e, também, a língua nacional. Geralmente, os professores trabalhavam aspectos sobre a nacionalidade num primeiro período da aula em língua polonesa, e no outro período, na língua de origem. Após essa intensificação da fiscalização em relação as escolas étnicas, ocorreu o fechamento de muitas delas, pois não conseguiram mais resistir a nacionalização, foram obrigadas a seguirem as medidas impostas pelo governo.

Com o fechamento dessas escolas isoladas particulares, surgiram as escolas subvencionadas onde o prédio escolar pertencia a comunidade e o professor era remunerado pelo estado ou município; mais tarde, também as escolas públicas foram implantadas na área rural como foi o caso da Escola Presidente Costa e Silva na localidade da Linha Polonesa (Cruz Machado - PR), na década de 1970. Verifica-se, no entanto, que mesmo após uma longa trajetória e mudanças nas políticas públicas educacionais, esse modelo de escola multisseriada ainda persiste e segue impregnado de resquícios de tradições culturais provindas dos primeiros descendentes de imigrantes que se estabeleceram na localidade.

\section{A ESCOLA MULTISSERIADA DA LINHA POLONESA EM CRUZ MACHA- DO (PR): HISTÓRIA, MEMÓRIA E PRÁTICAS PEDAGÓGICAS}

O Núcleo Colonial de Cruz Machado, criado em 1910, recebeu inicialmente imigrantes poloneses que chegaram por volta do ano de 1911. Esses advindos do município de Mallet (PR) estabeleceram-se na região denominada Pátio Velho e, em seguida, Rio do Banho. Ali foram alojados em pequenas e improvisadas casas. Essas instalações temporárias serviram para acomodá-los até que recebessem suas terras.

A pequena comunidade não dispunha de recursos para erguer uma escola e uma Igreja, portanto essas duas instituições, inicialmente, dividiram esse espaço que Revista X, v. 15, n. 6, p. 341-359, 2020. 
atendia a essas duas funções (figura 1). Rockenbach (1996, p. 28) ressalta o início destas organizações dizendo que "nos anos de 1912 funcionou a primeira escola do Rio do Banho, construída pelos colonizadores, sendo precursoras no ensino da época as irmãs Marta Jugehowski, Aloisa Bodecki e Anila Bodecki”.

\section{FIGURA 1 - PRIMEIRA ESCOLA CONSTRUÍDA PELOS POLONESES, EM 1912, NA LOCALIDADE DE RIO DO BANHO, NO MUNICÍPIO DE CRUZ MACHADO (PR)}

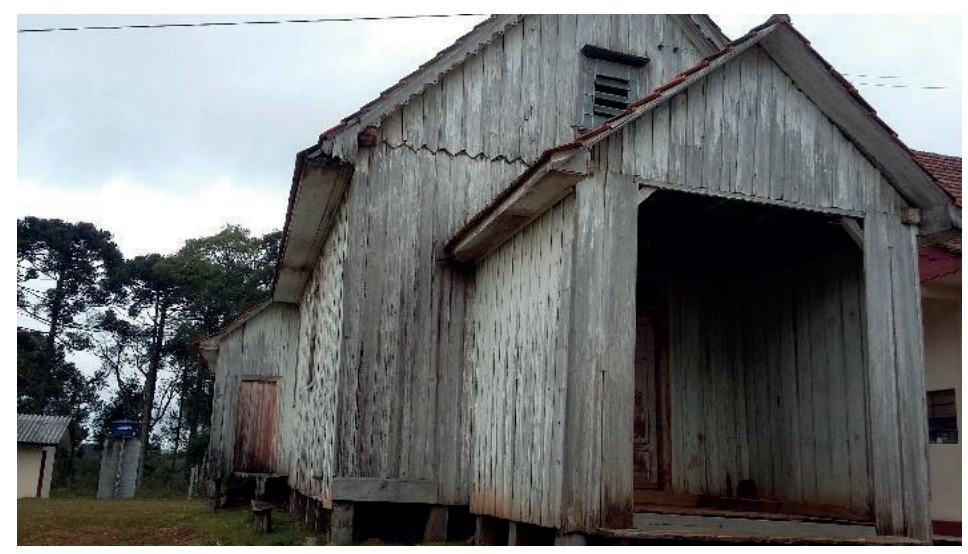

FONTE: Acervo particular da pesquisadora (foto tirada no ano de 2017)

Ainda sobre essa escola Marczal (2017) diz que depois de construído esse pequeno e simples espaço que atendeu os filhos dos primeiros imigrantes poloneses, foi construído um segundo espaço escolar "uma casinha perto da Igreja"; dessa vez, exclusivo para as atividades da escola. Savicki (2019) revela, ainda, que esse segundo espaço foi também construído em madeira, mas tinha uma área um pouco maior que o primeiro e apresentava biblioteca com uma coleção de cerca de quinhentos livros em polonês, recebidos de doações advindas da Polônia, e possuía um palco para teatro. Destacou a presença temporária das Irmãs Franciscanas da Sagrada Família de Maria, cuja congregação originara-se na Europa $^{3}$, as quais atuaram como professoras nessa escola. Comentou que essa escola

\footnotetext{
${ }^{3}$ Em 1857, o sacerdote Zygmunt Szczesny Felinski nascido em território que atualmente pertence a Ucrânia, fundou a Congregação das Irmãs Franciscanas da Sagrada Família de Maria em Petesburgo, capital do Império Russo, na tentativa de ajudar o povo polonês e as pessoas de outras etnias. $\mathrm{O}$ trabalho dessas irmãs esteve relacionado à instrução, às crianças, aos idosos, aos doentes e a todos que precisavam de algum tipo de ajuda. Suas atividades estenderam-se para a Polônia e a outros países europeus, fundando centros educacionais, asilos e hospitais. A convite dos padres poloneses no Brasil, essas irmãs chegaram no país, em 1906, iniciando seus trabalhos nas colônias polonesas de Orleans, Murici e D. Pedro II no município de Curitiba (PR). (GRYBOSI; VIEIRA, 2019).
} 
foi posteriormente demolida, dando lugar a Escola Isolada Agricultor do Rio do Banho, construída um pouco mais distante da primeira Igreja.

A medida que surgiam outras gerações, essa população de descendentes foi procurando novos espaços e deram origem a outras novas comunidades. Essa foi a trajetória dos imigrantes que passaram a habitar a região da Linha Polonesa (Cruz Machado - PR). Quando ali se estabeleceram, aproximadamente em 1957, esses também desejaram para si uma escola e uma Igreja, tendo em vista que a comunidade mais próxima, Rio do Banho, ficava a uma distância de 15 quilômetros desse local.

Entretanto, somente no ano de 1970 foi fundada, nesse local, a Escola Presidente Costa e Silva, que teve suas atividades iniciadas em 1971. Anterior ao ano de 1970, as crianças residiam em casas de parentes que moravam em comunidades rurais providas de escolas. Segundo Federovicz (2019b) seus filhos "começaram [a estudar] lá no Rio do Banho, paravam lá na casa da vó deles, era pertinho da escola; e aqui não tinha nada". A construção da Escola Presidente Costa e Silva ocorreu por iniciativa dos moradores e o estabelecimento, inicialmente, também serviu como Igreja. Nessa década, a professora era contratada pelo poder público e a escola também recebia material escolar do governo.

A professora Francisca Milczuk foi a primeira educadora a trabalhar na Escola Presidente Costa e Silva no ano de 1971. Ela relembra realidades da escola e aspectos da sua prática pedagógica (MILCZUK, 2019b):

[...] nós só recebemos a escola. Os pais ajudavam a fazer as carteiras. Eram duplas, tinha até quatro alunos sentados, pois era comprida. A sala organizava-se por classes, primeira, segunda, terceira e quarta. As atividades eram ensinadas da nossa cabeça, porque não tinha nada [refere-se a material didático], a gente tinha que passar o conteúdo. [...] passava mais conta, cópia, caligrafia. Era isso que eu passava, pois não se tinha nada. Depois do ano de 1980 recebemos alguns materiais. [...] eu lecionava para o quarto ano uma atividade, para o segundo outra [...], era assim, tudo junto. [...] no recreio tinha brincadeira de roda, as crianças faziam, bate peteca, era só isso, por que não tinha nem bola. [...] eu aplicava alguns castigos: os alunos tinham que segurar um livro, de joelhos, na porta; ou, de joelhos nas pedrinhas [...] Atuei como professora nessa escola até o ano de 1982, depois veio a professora Helena, minha filha. Ela trabalhou dois anos, em seguida lecionou o professor Jeronimo [...]. (MILCZUK, 2019b).

Nesse relato observam-se as dificuldades enfrentadas pela primeira professora, as condições de trabalho e o modo de contornar as adversidades que iam surgindo no diaa-dia escolar. Esse relato indica a presença de muitas variáveis: formação profissional continuada, políticas educacionais, financiamento da educação básica, escolarização e 
cultura do profissional da educação, entre outras. Entretanto, pelo viés histórico, verificase que mesmo sob a égide da tecnologia educacional, estabelecida nos anos de 1970, propondo novas tecnologias de ensino e novos materiais didáticos a fim de contribuir com as proposições de modernização do Brasil, a realidade da comunidade da Linha Polonesa estava, ainda, bem distante. Nesse momento, valorizava-se a introdução de recursos audiovisuais como uma expectativa de renovação didática, bem como a aplicação de "conhecimentos científicos fundamentados na psicologia da aprendizagem, na teoria da comunicação e na teoria sistêmica na solução de problemas educacionais" (SOUZA, 2013, p. 115). Essas promessas de modernização ainda não tinham chegado a essa escola multisseriada rural.

Delonzek (2019), estudante da Escola Presidente Costa e Silva entre os anos de 1976 a 1979, comenta a respeito do conteúdo aprendido:

[...] primeiro ensinavam os números, um dois, até dez, e depois aumentava. Depois, passava-se, no terceiro ano, para as continhas de menos, mais, vezes e dividir. Também, havia os pontos sobre as capitais dos estados. [...] tudo isso a gente copiava do quadro no caderno, aí estudava, para no outro dia, falar para a professora. [...] tinha exercícios para casa sempre. [...] no início tive dificuldades porque em casa só conversávamos em polaco, e na escola não; somente em brasileiro, aí pedia para os colegas fazer a lição ou me contar o que estava escrito [...]. A professora era bem rigorosa, se nos comportássemos mal, ficávamos de castigo (DELONZEK, 2019).

As memórias dessa estudante relatam a dificuldade de comunicação em relação ao não conhecimento da língua portuguesa. Staniszewski (2014, p. 135) comenta que "era comum, mesmo nos anos 1960, 1970 e 1980, existirem alunos cujos pais cultivavam a língua polonesa na família, por isso o professor tinha que falar em polonês e traduzir para o português para conseguir ensinar as crianças". O combate contra o estrangeirismo, nas escolas, ocorrido na década de 1930, não eliminou totalmente a cultura dos imigrantes. E essa cultura polonesa foi perpetuada também na escola, pois a maioria dos estudantes eram oriundos dessa etnia, cultivavam valores, língua, religião, costumes, hábitos alimentares comuns. Segundo Julia (2001, p. 21) a cultura escolar é descrita "como um conjunto de normas que definem conhecimentos a ensinar e condutas a inculcar, e um conjunto de práticas que permitem a transmissão desses conhecimentos e a incorporação desses comportamentos". O ambiente escolar estava permeado pela cultura polonesa e práticas inerentes a esta.

Federovicz (2019a), estudante entre os anos de 1977 a 1981, relembra os conteúdos 
que aprendia na escola: “[...] a gente fazia bastante conta, falava a tabuada, fazia caligrafia. [...] lembro que tinha sempre lição para casa, e ai de quem não fizesse! Uma vez fiquei de castigo no milho, por isso sempre lembrava de fazer a lição".

O relato evidencia as punições recebidas no interior da escola. Por longos anos a escola aplicou castigos físicos como forma de corrigir o comportamento dos estudantes e punir "a não aprendizagem" do aluno. Esse rigor disciplinar acompanha a educação há muito tempo, Julia (2001, p. 22) ao discorrer sobre o sistema severo dos colégios Jesuítas diz que o remodelamento dos comportamentos, interfere na "profunda formação do caráter e das almas que passa por uma disciplina do corpo e por uma direção das consciências".

Nota-se que a escola repetia os comportamentos das famílias, pois tratavam-se de famílias tradicionais, católicas e muitas vezes, numerosas, onde aplicavam-se castigos como forma de controle de comportamentos e de formação de caráter.

Federovicz (2019c), que foi estudante da escola entre os anos de 1971 e 1974, destaca outras situações de castigos físicos:

\begin{abstract}
A professora dava catequese, geralmente nas sextas feiras, depois do recreio. A Igreja era junto com a escola. A professora era muito rigorosa. Quando os alunos cometiam algum tipo de indisciplina, ficavam de castigo [...]. A matéria era passada no quadro e nós copiávamos no caderno. Levávamos lição para casa e, no outro dia, era tudo corrigido (FEDEROVICZ, 2019c).
\end{abstract}

Os castigos faziam parte da prática pedagógica dos professores, apresentavam-se como um auxílio disciplinar. Santana (2016, p.3) ressalta que "os professores praticavam formas dolorosas de punições como: beliscões, puxões de orelha, palmatória, ajoelhar-se no milho ou feijão. Formas que agrediam a integridade física e psicológica do educando e promoviam a subordinação". Fez-se o uso destas práticas variadas para manter a ordem e obediência dentro e fora de sala de aula. Foram amplamente aceitos pelas famílias, pois também no interior dessas tornava-se uma prática comum. Quanto aos castigos físicos Milczuk (2019a) afirma que:

Se a gente aprontasse, a gente ficava de castigo, às vezes de joelho nas pedrinhas, segurando o livro [...]. Antigamente era mais rígido. Lembro mais das bagunças: a gente trocava até pão com os colegas. Meu colega levava pão com mel, e como meu pai não cultivava mel, eu trocava o lanche com o meu amigo. A escola não fornecia merenda, cada um tinha que levar. E às vezes a professora fazia uma vaquinha, para fazer um sopão. (MILCZUK, 2019a). 
As "bagunças" a que se refere Milczuk (2019a) ocorriam em decorrência da falta de homogeneidade de faixa etária dos estudantes dessas classes multisseradas, eles tornavam-se autônomos muito cedo, pois tinham que percorrer longas distâncias para deslocarem-se até a escola, outros tinham que conduzir os irmãos menores, etc. Percebese o baixo poder aquisitivo das famílias agricultoras, trabalhavam na lavoura, cultivando milho, feijão, batatas e legumes para a sobrevivência. Ainda não havia a distribuição da merenda escolar. Essa precariedade de recursos transfere-se também para o interior da escola, no relato de Cieniuk (2019) que foi professor na Escola Presidente Costa e Silva entre os anos de 1986 a 1990, ele relata: "quando eu cheguei aqui tinha doze alunos, depois fui de casa em casa, convidando as crianças e aumentou para vinte e oito alunos. Recebia um pouco de material das outras escolas, mas não tinham muito recursos". Kurabaski e Martiniak (2016) apontam que esses recursos escassos eram insuficientes em outras áreas: falta de materiais didáticos, carteiras em número reduzido, falta de higiene entre outros.

Segundo Milczuk (2019a), estudante entre os anos de 1983 a 1986, a religiosidade estava muito presente nas práticas pedagógicas da escola, pois lecionavam-se conteúdos de ensino religioso, predominando a religião católica e a íntima ligação com a comunidade religiosa local: "a gente rezava, cantava, a professora Helena ensinava a gente a cantar, para cantar bonito na missa, azar se um de nós faltasse ou cantasse errado no dia da missa: na segunda-feira ela cobrava. A professora era nossa catequista".

Percebe-se uma forte presença da religiosidade inserida no contexto escolar, onde a professora exigia postura e primava pela perpetuação religiosa e cultural. A Igreja localizava-se a apenas alguns metros da escola (figura 2), e, embora a constituição brasileira determinasse um estado laico, a professora fosse funcionária pública, a escola fosse mantida pelo poder público, a religiosidade ainda estava intensamente presente no interior da escola ainda na década de 1970. 


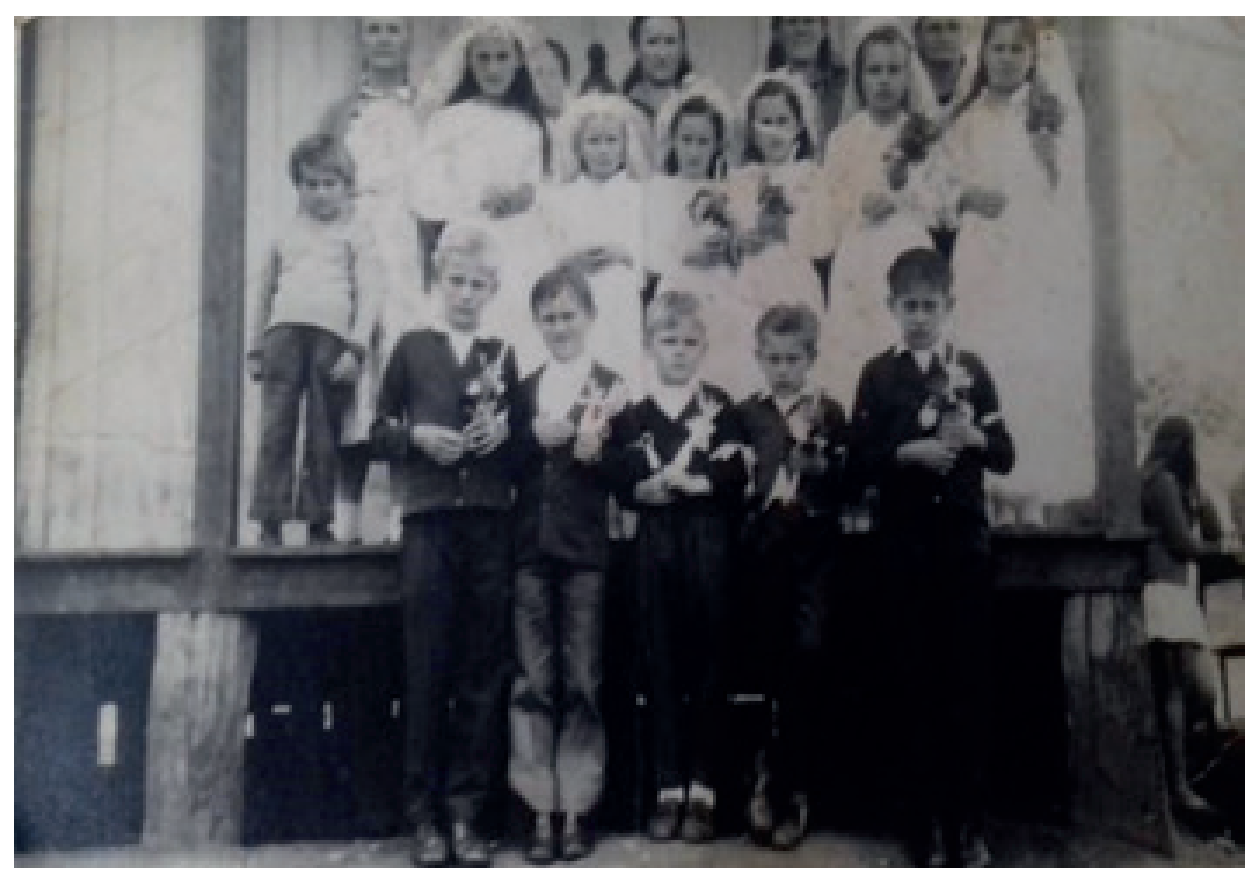

FONTE: Acervo particular de Cezaria Federovicz.

Benthien (2005, p. 27) em seus estudos contribuiu dizendo que "a Igreja foi uma instituição que mais exaltou o sentimento de polonidade do camponês, dando-lhe sentido de pertencimento a uma identidade, existente mesmo quando perseguido e humilhado". Essa tradição perdurou desde as duras perseguições e opressões sobre o povo polonês ainda na Europa. Essa ação missionária ocorreu também em terras brasileiras. A população imigrante depositou sua confiança nas congregações religiosas, principalmente pela empatia nas tradições, costumes e língua pátria.

Reaver a memória social produzida sobre uma experiência coletiva, possibilita compreender como situações vividas por determinadas comunidades são representadas por diferentes indivíduos. Esse fato torna-se relevante para reescrever a história de criação e funcionamento dessas escolas multisseriadas, em comunidades rurais de origem étnica, pois a história oral auxilia na preservação do patrimônio sócio histórico de um lugar, "sejam os espaços, objetos, monumentos, ruas, praças, pessoas. Normalmente, esses aspectos compõem o mosaico dos lugares de memória e, precisam ser preservados para a comunicação e continuação da história" (SANTOS, 2015, p. 1). 
A escola continua suas atividades até a atualidade (figura 3), o prédio sofreu alterações físicas, entretanto está localizado no mesmo local de sua origem e próximo a Igreja católica ${ }^{4}$.

\section{FIGURA 3 - ESCOLA PRESIDENTE COSTA E SILVA, NA LOCALIDADE DE LINHA POLONESA (MUNICÍPIO DE CRUZ MACHADO- PR), 2019}

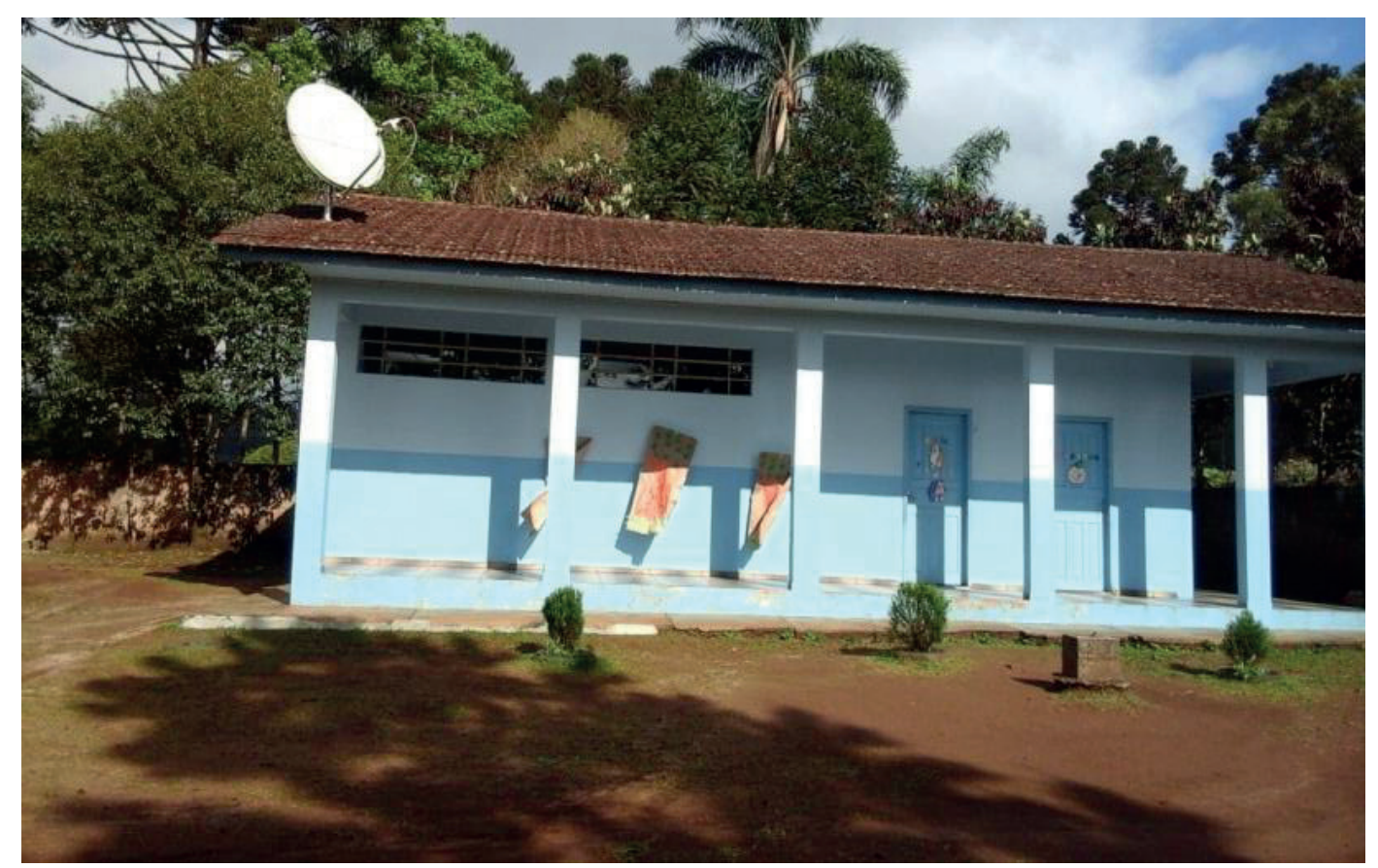

Fonte: Acervo da pesquisadora

Esses fragmentos, sobre a história dessa instituição, descritos a partir da história e memória oral dos sujeitos que, direta ou indiretamente, fizeram parte dessa instituição escolar, possibilitaram "identificar o modo como em diferentes lugares e momentos, determinada realidade social foi construída, pensada, dada a ler [...]" (CHARTIER, 1990). Percebeu-se uma complexa engrenagem cultural e social que resultou na formação cultural dessa população imigrante.

\footnotetext{
${ }^{4}$ Atualmente o professor Waldir Federovicz, leciona para uma classe de 25 alunos, ainda na modalidade multisseriada. Este reside próximo à localidade, deslocando-se diariamente para atender os seus alunos, recebe formação continuada da Secretaria Municipal de Educação do Município de Cruz Machado (PR), o qual situa-se a uma distância de 30 quilômetros dessa comunidade.
} 


\section{APONTAMENTOS}

Embora o objetivo dessa pesquisa volte-se para o resgate de fatos sobre a fundação da escola e a sua prática educativa, percebe-se que o contexto sócio histórico e econômico apresenta-se bem mais amplo. Não se trata apenas de verificar as condições de funcionamento ou deixar transparecer o cotidiano da escola. As questões que surgem apresentam-se complexas.

Voltando ao final do século XIX e início do século XX, quando os primeiros imigrantes chegaram à região, observou-se um interesse do Brasil em povoar as terras desabitadas do sul do país. Em virtude da libertação dos escravos (1888) o país necessitaria de mão de obra. Com o intuito de substituir essa modalidade de trabalho, os imigrantes foram "convidados".

Percebeu-se a dificuldade das primeiras famílias, pois primeiramente estabeleceram-se em moradias improvisadas até que seus lotes ficassem definidos. Esses povos desconheciam o clima, a terra, as sementes a serem plantadas, etc. Além disso enfrentaram a doença, a febre tifoide que dizimou muitas pessoas. Outros tiveram que ser transferidos para localidades distantes pelo fato de adquirirem terras fracas, e, assim iniciou-se a saga desse povo (ROCKENBACH, 1996).

Depois de estabelecidos, vieram novas necessidades como foi o caso da escola. Por iniciativa própria muitos núcleos construíram suas escolas e receberam o auxílio da Igreja. Observou-se que nesse momento, final do século XIX e início do século XX, a Europa passava pelo movimento positivista, absorvido por um pensamento cientificista. Novas ideias disseminavam-se e propagava-se a implantação do estado laico e da escola laica. Esse fato disparou um movimento religioso denominado ultramontanismo que disseminou congregações religiosas por todo o mundo, inclusive na América, com o intuito de ações missionárias em prol da evangelização. Essa atitude refrearia a cultura laica e prolongaria a subsistência de instituições intimamente ligadas a religião católica, entre elas a escola.

Inicialmente a presença das congregações religiosas, auxiliando a manter a escola, não ocasionou estranheza, pois a escola pública não tinha ainda, condições de atender as demandas da escolarização das crianças. Entretanto, no Governo Getúlio Vargas, houve um forte movimento nacionalista que impediu essas instituições de funcionarem, tendo em vista que se exigiam professores natos ou naturalizados, desejava-se o ensino da língua portuguesa e os estudos da história e geografia brasileira, entre outros. As escolas tiveram que adaptar-se a essas novas políticas. Entretanto, o que se percebeu foi que a 
língua ensinada no interior da escola não era a mesma que os alunos falavam em casa. As famílias imigrantes transmitiam a cultura de origem em casa e por meio da igreja (cantos, orações, catequese...). Quando a escola Presidente Costa e Silva foi criada já havia se passado quatro décadas dessa proposta de nacionalização, entretanto ainda existiam crianças que, em casa, aprendiam a língua polonesa como primeira língua.

No ano de criação da Escola Presidente Costa e Silva foi implantada a Lei 5692/71, cuja tendência tecnicista vinha de encontro com uma nova realidade econômica brasileira. Desta vez o país encontrava-se em acelerado processo capitalista com a chegada de grandes multinacionais e reorganizava o ensino fundamental em dois ciclos: $1^{\circ}$ e $2^{\circ}$ grau. Essa suposta industrialização trouxe consequências para as comunidades rurais, pois houve, também, um processo de êxodo, onde a população rural procurava emprego nas indústrias ${ }^{5}$. Esse fato reduziu a população dessas comunidades, o que fez com que a escola ainda consistisse de uma única sala, cuja metodologia mantinha a modalidade multisseriada.

A lei 5692/71 estabelecia no ensino de $2^{\circ}$ grau um ensino técnico profissionalizante e no $1^{\circ}$ grau previa algumas disciplinas que preparassem o estudante para essas atividades profissionais. As disciplinas constavam de técnicas comerciais e industriais, e, também trabalhos manuais, “[...] nas sextas feiras ela ensinava a bordar, desenhar, trançados de broia" (DELONZEK, 2019). Embora essas pequenas iniciativas, por conta da legislação vigente, estivessem no interior da sala de aula, a precariedade de recursos ainda existia. Percebe-se, nesse contexto, uma população de descendentes de imigrantes já na segunda geração lutando por condições favoráveis de escolarização para uma terceira geração (seus filhos) e, ainda, persistindo as mesmas dificuldades dos ascendentes que aportaram as terras brasileiras: "[...] nós só recebemos a escola. Os pais ajudavam a fazer as carteiras. [...] As atividades eram ensinadas da nossa cabeça, porque não tinha nada [refere-se a material didático], a gente tinha que passar o conteúdo" (MILCZUK, 2019b).

Em Julia (2001, p. 2) encontra-se a cultura escolar inserida numa abordagem histórica, como sendo uma mistura de normas e práticas, aquelas "que definem conhecimentos a ensinar e condutas a inculcar" e como um conjunto "que permite a transmissão desses conhecimentos e a incorporação de comportamentos". No cotidiano da Escola Presidente Costa e Silva visualiza-se essa cultura escolar sendo apreendida por meio dos conteúdos escolares transmitidos e também, por meio de conteúdos religiosos

\footnotetext{
${ }^{5}$ Nesse caso a população da Linha Polonesa e outras regiões (Cruz Machado - PR) deslocava-se em direção à cidade de União da Vitória (PR) que se apresentava como alternativa, pois consistiase num grande polo industrial madeireiro.
} 
ensinados no interior da escola. A escola é uma instituição da sociedade, portanto uma entidade que reproduz influências sociais, em todos os âmbitos, e além disso, os atores, sejam professores ou alunos e seus familiares, também contribuem para a construção dessa cultura escolar. Aqui percebe-se, o que Benthien (2005) denomina de sentimento de "polonidade", alunos descendentes de imigrantes poloneses, professores também descendentes de poloneses, uma comunidade pequena absorvida pela cultura e língua polonesa e tradicionalmente religiosa desde seus antepassados.

Embora essa colônia de descendentes de imigrantes poloneses tenha passado por diversas adversidades, desde seus antepassados, quer seja em âmbito econômico, ou em termos de organização da escola, a escolarização foi um dos principais fatores de desenvolvimento para essa população (GRYBOSI; VIEIRA, 2019).

\section{CONSIDERAÇÕES FINAIS}

A década de 1970, na área educacional, ficou conhecida historicamente como a década das novas tecnologias educacionais. A tendência tecnicista que surgia estimulava o uso de novas tecnologias de ensino e materiais didáticos, especialmente recursos audiovisuais supervalorizados. Essa otimização de recursos resultou da consequência de um novo modelo econômico que se instaurava no país. As indústrias multinacionais passavam a fazer parte do novo cenário econômico brasileiro e a legislação educacional (Lei 5692/71) teve que alterar os graus de ensino, e estimular cursos profissionalizantes em nível médio, a fim de atender a esse novo contexto sócio econômico.

Mesmo diante essa realidade percebeu-se que a Escola Presidente Costa e Silva, da Linha Polonesa, não acompanhou a evolução educacional esperada. Os recursos financeiros e didáticos apresentavam-se escassos e os recursos tecnológicos não adentraram a escola. A língua polonesa aprendida, nas famílias, ainda era um impedimento para a aprendizagem escolar. $\mathrm{O}$ modelo de escola multisseriada desativado a muito tempo em outras localidades, continuou a existir até o século XXI. Conclui-se que mesmo diante de grandes inovações tecnológicas da atualidade, exigências de formação docente e novas políticas educacionais, ainda existem realidades muito peculiares que se servem de experiências do passado para oferecer escolarização aos estudantes.

Esse trabalho deixou transparecer a influência cultural de um povo que se estabeleceu em terras brasileiras, implantou a escola a sua maneira e contou com a ajuda de congregações religiosas, transferiu-se de lugar em busca de melhores condições de vida e continuou a luta pela educação dos seus descendentes. A pesquisa, ainda, 
possibilitou mapear mais uma escola de origem étnica polonesa na região sul do estado do Paraná, contribuindo, de forma micro com a história da educação local e regional, e de forma macro com o grande mosaico de escolas espalhadas pelo Brasil, oferecendo consistência à história da educação brasileira. "Miło mi pana Poznać” (muito prazer)... escola multisseriada da Linha Polonesa.

\section{Agradecimentos}

Agradecimentos especiais as pessoas que se dispuseram a participar das entrevistas sobre a história da escola e da comunidade local; ao Núcleo de Catalogação, Estudos e Pesquisas em História da Educação (NUCATHE) da Universidade Estadual do Paraná (UNESPAR), campus de União da Vitória, pelo apoio quanto ao tratamento das fontes pesquisadas. 


\section{REFERÊNCIAS:}

BENTHIEN, Muriéli Silveira Boeira. Poloneses da Colônia São Bento (1870-1930). 2005.98 f. Dissertação (Mestrado em História) - Programa de Pós Graduação em História, Centro de Filosofia e Ciências Humanas, Universidade Federal de Santa Catarina, Florianópolis, 2005. Disponível em: <https://core.ac.uk/download/pdf/30383024.pdf>. Acesso em: 15 set 2019.

CHARTIER, Roger. A História Cultural: entre práticas e representações. Lisboa: DIFEL, 1990.

CIENIUK, Jerônimo. Entrevista concedida a Vanessa Federovicz. Cruz Machado (PR), 17 de janeiro de 2019. Gravação em áudio. (Entrevista).

DELONZEK, Natália. Entrevista concedida a Vanessa Federovicz. Cruz Machado (PR), 08 de setembro 2019. Gravação em áudio. (Entrevista).

FEDEROVICZ, André. Entrevista concedida a Vanessa Federovicz. Cruz Machado (PR), 03 de fevereiro de 2019. Gravação em áudio. (Entrevista).

FEDEROVICZ, Cesária. Entrevista concedida a Vanessa Federovicz. Cruz Machado (PR), 17 de janeiro de 2019. Gravação em áudio. (Entrevista).

FEDEROVICZ, João. Entrevista concedida a Vanessa Federovicz. Cruz Machado (PR), 17 de janeiro de 2019. Gravação em áudio. (Entrevista).

GRYBOSI, Roseli Teresinha Bortolan; VIEIRA, Alboni Marisa Dudeque Pianovski. Educar e Construir, Irmãs Franciscanas da Sagrada Família de Maria nas Colônias. Curitiba: Appris, 2019.

JULIA, Dominique. A Cultura escolar como objeto histórico. Revista Brasileira de História da Educação, São Paulo, jan/ jun 2001. p. 9 - 43.

KREUTZ. Lucio. Educação de Imigrantes no Brasil. In: LOPES, Eliana Marta Teixeira, FARIA FILHO, Luciano Mendes VEIGA, Cynthia Greive. (orgs.). 500 anos de educação no Brasil. 2. ed. Belo Horizonte: Autêntica, 2000. p. 348.

KUBASKI, Luciana, MARTINIAK, Vera. A Educação Escolar dos Imigrantes Poloneses no Paraná. 2016. In: Seminário Nacional do HISTEDBR, 10., 2016, Campinas-São Paulo. Anais.... Disponível em: <https:/www.fe.unicamp.br/eventos/histedbr2016/anais/ pdf/1034-2880-2-pb.pdf>. Acesso em: 15 de set. 2019. 
MALIKOSKI, Adriano; KREUTZ, Lúcio. Escolas étnicas polonesas no Rio Grande do Sul (1875-1939). Hist. Educ., Santa Maria, v. 21, n. 51, p. 317-331, abr. 2017. Disponível em: $<$ http://www.scielo.br/scielo.php?script=sci_arttext\&pid=S2236-34592017000100317\& lng=pt\&nrm=iso $>$. Acesso em: 10 de jul. 2019.

MARCZAL, Ceslau. Entrevista concedida a Roseli B. Klein. Cruz Machado (PR), 02 de julho de 2017. Anotações por escrito. (Entrevista).

MARTINIAK, Vera Lucia. As Escolas Étnicas no Paraná. In: CONGRESSO NACIONAL DE EDUCAÇÃO - EDUCERE, 11., 2013, Curitiba. Anais... Disponível em: $<$ http://educere.bruc.com.br/ANAIS2013/pdf/9090_5428.pdf $>$. Acesso em 15 de jul. 2019.

MILCZUK, Ari. Entrevista concedida a Vanessa Federovicz. Cruz Machado (PR), 05 de fevereiro de 2019. Gravação em áudio. (Entrevista).

MILCZUK, Francisca. Entrevista concedida a Vanessa Federovicz. Cruz Machado (PR), 08 de fevereiro de 2019. Gravação em áudio. (Entrevista).

RENK, Valquíria Elita. A escolarização da infância nas escolas étnicas eslavas do Paraná: Uma experiência singular na história da educação. In: CONGRESSO NACIONAL DE EDUCAÇÃO - EDUCERE, 11., 2013, Curitiba. Anais.... Disponível em: $<$ https://www.google.com.br/url?sa=t\&source=web\&rct=j\&url=http://educere.bruc. com.br/arquivo/pdf2013/7134_4232.pdf>. Acesso em: 20 de jul. 2019.

RENK, Valquíria Elita. Nacionalização Compulsória das Escolas Étnicas e Resistências, no Governo Vargas. In: CONGRESSO NACIONAL DE EDUCAÇÃO - EDUCERE, 14. 2008, Curitiba. Anais.... p. 4285-4296. Disponível em: <https://educere.bruc.com.br/ arquivo/pdf2008/620_436.pdf>. Acesso em: 20 de jul. 2019.

ROCKENBACH, Irene Fryder. Dados Históricos e Memórias de Cruz Machado. Cuiabá: [s/e], 1996.

SANTANA, Joelma Gonçalves Santos. Os Castigos Utilizados para Disciplinar Alunos: influência da ação jesuítica nas práticas escolares do século XIX. Concepções - Revista Científica da Faculdade São Luís de França/FSLF, Aracaju, ano IV, ed. 4, dez. 2013. Disponível em: <https://portal.fslf.edu.br/wp-content/uploads/2016/12/tcc_13.pdf>. Acesso em: 16 de set. 2019. 
SANTOS, Mariângela Santana Guimarães. Memória e História: contributos da história oral para a preservação da cultural. In: SIMPÓSIO NACIONAL DE HISTÓRIA, 28., 2015, Florianópolis. Anais... Disponível em: $<$ http://www.snh2015.anpuh.org/resources/anais/39/1434411171_ARQUIVO_ANPHUMEMORIAEHISTORIA-Artigo_OKK1.pdf >. Acesso em: 20 de set. 2019.

STANISZEWSKI, Rosane. Uma Investigação sobre o Ensino da Matemática nas Escolas Polonesas em São Mateus do Sul, Paraná. 2014. 179 f. Dissertação (Mestrado em Educação em Ciências e em Matemática) - Setor de Ciências Exatas, Universidade Federal do Paraná, Curitiba, 2014.

SAVICKI, Tereza. Entrevista concedida a Vanessa Federovicz. Cruz Machado (PR), 18 de janeiro de 2019. Gravação em áudio. (Entrevista).

SOUZA, Rosa Fátima de. Objetos de Ensino: a renovação pedagógica e material da escola primária no Brasil, no século XX. Educar em Revista, Curitiba, n. 49, jul./set. 2013, p. 103-120. Disponível em: <http://www.scielo.br/pdf/er/n49/a07n49.pdf>. Acesso em: 20 de jul. 2019.

WACHOWICZ, Ruy Christovam. O Camponês Polonês no Brasil. Curitiba: Fundação Cultural Casa Romário Martins, 1981. 